\title{
Das materialidades da escola: o uniforme escolar
}

Ivanir Ribeiro

Vera Lucia Gaspar da Silva

Universidade do Estado de Santa Catarina
Correspondência:

Ivanir Ribeiro

Instituto Federal de Educação de Santa Catarina

Rua 14 de Julho, 150

88075-010 - Florianópolis/SC

ivanir@ifsc.edu.br

\section{Resumo}

Este texto dedica-se a situar o uniforme escolar como objeto histórico e como importante fonte do e no universo escolar. Para tanto, empreende-se uma revisão da literatura que aborda a temática e investe-se em uma reflexão que concebe esse artefato como uma das expressões da materialidade que dá contornos à forma escolar, tomando-o na perspectiva da cultura material. Alguns autores servem aqui de referência: Richard Bucaille, Jean-Marie Pesez e Ulpiano Bezerra de Meneses, nos estudos em que se dedicam à cultura material; Agustín Benito Escolano e Rosa Fátima de Souza, nos trabalhos em que voltam o olhar para cultura material escolar; Inês Dussel e Katiene Nogueira da Silva, autoras que abordam diretamente a questão dos uniformes escolares. Não menos importantes para efeitos deste artigo são os trabalhos que tratam do movimento higienista, particularmente aqueles levados a cabo por José Gondra. Os dados levantados e as reflexões efetuadas indiciam dois movimentos (ou tensões) nada desprezíveis. Por um lado, são evidentes as dificuldades encontradas para adoção dos uniformes escolares por todos os alunos, tanto por parte do Estado quanto por parte das famílias, devido ao fato de eles representarem um custo elevado, principalmente os calçados, artigos pouco utilizados pela maioria da população até, no mínimo, meados do século XX. Por outro lado, há indícios de que esse traje desempenhava uma função niveladora importante. Por meio dele, criava-se uma ideia de padronização e democratização do ensino, mesmo que em aparência, além de se dar visibilidade pública a uma instituição social cada vez mais importante: a escola.

\section{Palavras-chave}

Uniforme escolar - Cultura material escolar - Objetos da escola. 


\title{
On the materialities of school: the school uniform
}

Ivanir Ribeiro

Vera Lucia Gaspar da Silva

Universidade do Estado de Santa Catarina

\begin{abstract}
This text is devoted to situate the school uniform as a historical object, and as an important source on and in the school universe. For that, a literature survey is carried out on this theme, and a reflection is conducted envisaging this artifact as one of the expressions of materiality that give shape to the school form, considering it under the perspective of the material culture. Some authors are used here as references: Richard Bucaille, Jean-Marie Pesez and Ulpiano Bezerra de Meneses in the studies dedicated to material culture; Agustin Benito Escolano and Rosa Fátima de Souza for the works that turn their attention to the material school culture; Inês Dussel and Katiene Nogueira da Silva, authors that deal directly with the issue of school uniforms. Of no less importance for this article are the works that deal with the hygienist movement, particularly those developed by José Gondra. The data gathered and the reflections conducted review two movements (or tensions) not at all negligible. On the one hand, there are evident difficulties found in the adoption of school uniforms for every student, both on the side of the State and on the side of the families, due to the fact that uniforms represent a high cost, especially shoes, an article of limited usage by the majority of the population until at least the mid-20th century. On the other hand, there are indications that this apparel did perform an important leveling function. Through it, the idea was created of the standardization and democratization of teaching, even if only in appearance, apart from giving public visibility to an ever more important social institution: the school.
\end{abstract}

\section{Keywords}

Contact: Ivanir Ribeiro

School uniform - School material culture - School objects.

Instituto Federal de Educação de Santa Catarina

Rua 14 deJulho, 150

88075-010 - Florianópolis/SC

ivanirpsi@gmail.com 
Dentre um conjunto de elementos materiais que compõem a escola e sua cultura está o uniforme, materialidade aqui concebida como um dos elementos constitutivos da cultura escolar. Este texto dedica-se a situar tal objeto do ponto de vista da reflexão teórica e sistematizar aquilo que parte dos autores ocupados com o assunto e com temas correlatos tem produzido, articulando discussões do campo da cultura material. Como referência empírica, são apresentados alguns dados da história da educação catarinense.

Seguindo as indicações de Ulpiano Bezerra de Meneses (2005), tomamos os artefatos não apenas como produtos, mas também como vetores de relações sociais. Nas palavras do autor, "a chamada 'cultura material' participa decisivamente na produção e reprodução social” (p. 18). Para essa mesma perspectiva apontam os estudos dos franceses Jean Boudrillard (1968) - que considera que, para além dos atributos físicos dos objetos (características e propriedades), há que se considerar o sentido historicamente atribuído a eles pelos grupos sociais - e Daniel Roche (2000) - que adverte que os objetos não podem ser reduzidos a uma simples materialidade, mas devem, ao contrário, ser recolocados em "redes de abstrações e sensibilidades essenciais à compreensão dos fatos sociais" (p. 13), nas quais também estão envolvidas relações de produção e consumo.

Voltando-se para uma análise mais interna ao âmbito das instituições escolares, as reflexões do espanhol Agustín Escolano Benito (2010) induzem à desnaturalização dos objetos, que não podem ser vistos como neutros, já que sua incorporação às práticas escolares comporta significados e valores que são adicionados à sua materialidade física e funcional e definem modos de pensar o ensino. 0 autor acrescenta, ainda, que os objetos não são autônomos e atemporais, mas sim produções culturais que falam de nossas tradições, de nossos modos de pensar e sentir e de nossa memória individual e coletiva. Para ele, ao se tomar o material, devem-se examinar seus significados culturais. Isso possibilitaria estruturar uma história holística da educação na busca da compreensão do uso dos objetos, das vinculações entre eles, de suas relações com os atores e com as práticas empíricas que são postas em ação, de sua localização nos espaços institucionais e, por fim, da imbricação entre as mediações que perpassam o ensino e os modos de produção.

Desse modo, ainda no rastro das proposições de Agustín Escolano Benito (2010), a valorização das fontes materiais para a história da escola supõe um giro epistêmico e social importante: por um lado, retoma a investigação histórica sobre o conhecimento das práticas culturais e sobre os modos de produção da cultura escolar em que os objetos dão visibilidade a essa cultura; por outro, atribui-se aos materiais uma importância que antes não possuíam, ao considerá-los como elementos empíricos que afetam a coletividade que foi educada, entre outras coisas, mediante dispositivos visíveis, ou seja, por meio de sua materialidade.

Empreender esforços para entender o uso dos uniformes escolares pressupõe, então, procurar indícios da história e da memória de uma dada instituição ou de um grupo, buscando desvendar os sentidos simbólicos que esse objeto adquiriu no universo escolar e social, desnaturalizando e historicizando seus usos. Os uniformes escolares - essas coisas diminutas, assim como os nomeia Inês Dussel (2005) - marcam os sujeitos de forma muito mais profunda do que podemos imaginar. Eles fazem parte de toda uma simbologia que perpassa as instituições escolares e que ainda precisa ser decifrada, compreendida, estudada. Essas coisas que nos ocupam todos os dias, tal como nos adverte Silvina Gvirtz (2005), não são menores; elas definem "silenciosamente la trama política de la escuela" (p. 12). A autora acrescenta que, para produzirem-se melhoras no sistema de ensino, é preciso pensá-lo numa relação recíproca entre o macro e o cotidiano, "desde lo que pasa cada dia em cada escuela, com cada maestro, com cada professor, com cada alumno" (p. 11). Nesse rastro, estudos mais recentes têm-se preocupado em adentrar aspectos escolares que materializam 
as instituições e que lhes dão forma, tais como o mobiliário, a arquitetura, os manuais de ensino, os uniformes, enfim, um leque de objetos e fontes por muito tempo considerados de menor importância e que passam a integrar estratégias para se estudar a cultura escolar e sua materialidade.

A cultura escolar é aqui também compreendida em suas regularidades e transformações, conforme tem apontado Rosa Fátima de Souza (2009), ou seja, a cultura escolar comporta aspectos que permanecem ao longo do tempo, como as "tradições, sedimentação de práticas, idéias, modos de fazer e pensar que governam o ensino, que perduram ao longo do tempo sobrevivendo às reformas e inovações" (p. 17); por outro lado, essa cultura também é dinâmica e transforma-se, como qualquer processo cultural.

\section{Uniforme escolar: materialidade que} educa e comunica

No caso das escolas públicas brasileiras, a instituição dos uniformes acompanha a expansão de sua rede, que tem a virada do século XIX para o XX como período singular. Não utilizamos aqui a expressão sistema de ensino por entender que este vai estruturar-se de forma mais orgânica um pouco mais tarde. Também não se faz a associação pura entre um modelo escolar e um regime de governo - neste caso, o republicano -, por entender que há indicativos suficientes na literatura da área para ampliar essa compreensão. Como referência importante, citamos os estudos reunidos no livro $A$ difusão mundial da escola, organizado por António Nóvoa e Jürgen Schriewer e publicado em 2000.

Das intenções iniciais para adoção dos uniformes, outras foram incorporadas e, apesar de eles terem sido descartados em alguns períodos de nossa história, não deixaram de ser adotados, seja como componentes de controle dos corpos, seja como estratégias de visibilidade a projetos institucionais e governamentais. Ainda hoje, tais artefatos constituem-se como elementos importantes na paisagem educacional e são aqui apresentados como expressão ou peça dessa cultura material escolar que continua a necessitar de investimentos e problematização. Trata-se de componentes que, como argumenta Inês Dussel (2005), operam aprendizagens

sobre quiénes deben vestirlo y quiénes no, quiénes tienen varios y quiénes solo uno, quiénes son parecidos e quiénes son diferentes, quiénes e cómo son limpios y prolijos y quiénes y como son sucios y desprolijos, cuál és el limite del pudor y la pulcritude, cuál debe ser considerada uma buena aparencia, hacen referencia a toda uma série de saberes sociales sobre la identidad y la diferencia que son fundamentales a la hora de imaginar nuestra sociedad. (p. 83)

Aqui, podem-se mencionar as reflexões de Umberto Eco (1989), quando esse autor, pautado em perspectivas da semiologia, aborda o vestuário como comunicação. Para ele, não se deve desconsiderar que a roupa serve principalmente para proteger o corpo do frio ou do calor e para ocultar a nudez, vista pela opinião pública das sociedades modernas como vergonhosa. Acima de tudo, o vestuário deve ser analisado como um artifício inventado para comunicar, sendo aquilo que se quer comunicar intrinsecamente relacionado aos aspectos culturais da sociedade em que se insere, ou seja, a noção de comunicabilidade do vestuário está inserida no quadro de uma vida em sociedade onde tudo é comunicação. Para o autor, "a indumentária assenta sobre códigos e convenções, muitos dos quais são fortes, intocáveis, defendidos por sistemas de sanções ou incentivos" (ECO, 1989, p. 15). Por isso, ela serve para transmitir certos significados e identificar posições. Nos trajes militares, por exemplo, o código do vestuário é articulado de tal forma que não permite nenhuma variante, ao contrário do traje civil, aberto a um maior número de variações desde as cores até a eleição dos sapatos.

Por outro lado, a escolha de um vestuário muda de significado segundo o contexto 
em que se insere. Às vezes, a ousadia é bem-vista; em outras, é execrada, normalmente dependendo da posição social da pessoa em questão. Articulamos essa ideia ao que Inês Dussel (2005), baseada nas obras dos historiadores franceses Philippe Perrot e Daniel Roche, classifica como parte de um regime de aparências. Para ela, as sociedades sempre se ocuparam e ainda se ocupam em produzir aparências sedutoras, em propor ordenamentos e percepções. Essa preocupação com a aparência remonta à própria origem da sociedade humana, com suas pinturas e seus ornamentos corporais, e até à complexidade dos vestidos, da arquitetura e da estética social. Nas sociedades burguesas dos séculos XVIII e XIX, por exemplo, o regime austero da aparência e sua preferência pela limpeza e pela opacidade articulavam-se à emergência de uma burguesia urbana oposta ao desenvolvimento ostentoso da nobreza. Vê-se aí a manifestação da necessidade de regular as aparências, de intervir sobre a apresentação das pessoas e das práticas coletivas. Nas escolas modernas, por sua vez, a construção de edifícios, a produção de materiais escolares com linguagem específica para os alunos, o ordenamento espacial de pessoas e objetos e a adoção do uniforme escolar também apresentam um regime de aparências que contribui para delimitar os contornos (ou seriam fronteiras?) da escola com o externo. Assim, a prática de uniformização transformou-se num elemento fundamental para a construção de um sistema educativo baseado no ideal de igualdade de oportunidade para todos, ainda que muitas vezes essa igualdade seja mais estética do que efetiva.

Inês Dussel (2007), servindo-se da teoria foucaultiana, analisa a adoção dos uniformes escolares também como parte de relações de poder que agem sobre o corpo e que, juntamente com outros procedimentos institucionais, produzem conformidades e individualidades na escola e na sociedade, modelando os indivíduos em suas relações com os outros e consigo mesmos. A esse respeito, a autora acrescenta: los indivíduos son producidos junto a otras instituiciones sociales como parte de la governamentalización de la sociedad. Esta producción implica el despliegue de tecnologias específicas que moldean tanto el cuerpo como el alma de los sujetos modernos, $\mathrm{y}$ pueden ser rastreadas em lo que llamaré el 'régime de apariencias', um sistema que regula cómo la gente y las cosas deben verse o mostrarse, cómo los cuerpos deben desempenãrse publicamente y cómo los espacios deben lucir para ser considerados educados. (DUSSEL, 2007, p. 133)

Nessa perspectiva, é por meio do corpo e das práticas sobre ele que se moldam os comportamentos; a regulação da vida social é, em primeiro lugar, a regulação dos corpos. Tomando-se essa premissa como uma das balizas da reflexão, não se poderia negligenciar o aparato de saberes científicos que se foi estruturando desde o início do século XIX, por intermédio da medicina e dos microbiologistas que têm no corpo e em sua regulação o ponto chave. No discurso, o ponto central é a luta contra o contágio e as enfermidades, mas, como aponta Inês Dussel (2005), o higienismo representou um movimento social amplo que, combinando questões urbanísticas, ecológicas, morais, políticas e de formação de consumidor, afirmou-se e tornou-se o discurso central no final do século XIX, servindo a diferentes projetos políticos.

\section{Prescrições higienistas para o bem vestir}

Baseando-se nos modelos dos higienistas franceses, os médicos brasileiros irão desenvolver um vasto programa de regras para o funcionamento das instituições escolares, com o intuito de preparar "sujeitos moral, física e intelectualmente sadios" (GONDRA, 2004, p. 168). As prescrições incluíam: o local mais adequado para a construção dos edifícios e sua arquitetura (tipos de cômodos, sistema de ventilação 
e iluminação); a nutrição e a hidratação dos alunos, estabelecendo desde a rotina alimentar, a quantidade de alimentos a ser ingerida, sua qualidade e variedade, as bebidas e os condimentos permitidos e proibidos, até as normas para o funcionamento das cozinhas; o programa de exercícios para os alunos; a eliminação dos resíduos corporais; a melhor forma de moldar os sentidos por meio da educação moral e intelectual; o vestuário e a higiene pessoal.

Ao tratarem da questão do vestuário, os higienistas retomam a discussão acerca do desafio do homem, desde os primórdios, para proteger o corpo das intempéries do ambiente. Partindo dessa preocupação, os médicos desenvolvem toda uma retórica para explicar a origem da matéria-prima utilizada para a fabricação dos tecidos, indicando os mais adequados para cada estação do ano. Podemos dizer que o vestuário, nesse sentido, representava uma função pragmática, ou seja, havia, em sua adoção, uma preocupação em proteger o corpo das influências físicas do mundo exterior (frio e calor), mas, tal como já vimos, as prescrições não eram assim tão desinteressadas. Uma passagem bastante ilustrativa das orientações dos médicos higienistas é a indicação do Dr. Coutinho (apud GONDRA, 2004) em sua tese de 1857:

Antes da puberdade o menino produz menos calorico, entretanto pelos jogos próprios da idade, pelos movimentos que elle executa, a produção do calorico é suficiente; segundo a diversidade das estações fazem-se necessários vestuários diversos, assim estabeleceremos: no verão os alumnos devem usar roupas de linho ou algodão, porque os tecidos destes vegetaes recebem e perdem o calorico rapidamente; no inverno devem usar roupas de lãa, porque recebem lentamente e guardão o calorico por mais tempo, e alem d'isto isolão o corpo da influência dos agentes esternos e conservão melhor a caloridade do corpo. A lãa tem outras vantagens, e o algodão, bem que em menos escala, participa d'ellas; estes tecidos não se impregnão promptamente de humidade como o linho, o que depressa molha-se, condensa o produto da transpiração cutânea e resfria o corpo; os tecidos de lãa e algodão deixão escapar pelas suas malhas os vapores aquosos, - não condensam a humidade, que molhando apenas o tecido logo se evapora. (p. 184)

José Gondra (2004) destaca que a preocupação com a descrição minuciosa dos tipos de tecidos (lã, seda, linho e algodão) cumpria uma dupla função no interior do discurso médico: ordenar a vestimenta dos educandos e regular o modo de se vestir das mulheres.

No que se refere à ordenação da vestimenta, as prescrições médicas abarcavam a forma mais adequada de usá-la e os cuidados que o aluno deveria ter com sua manutenção. No primeiro caso, os médicos orientavam que a vestimenta não poderia impedir o movimento dos alunos. Como exemplo disso, temos a defesa do Dr. Coutinho (apud GONDRA, 2004) de que "um vestuário apertado equivale a uma cadêa que tolhendo o desenvolvimento do corpo, póde predispor a enfermidades" (p. 184).

Dentre os cuidados com a vestimenta, havia prescrições para a troca das roupas de cama e do vestuário de dormir, além das roupas de uso diário: duas vezes por semana, devido à retenção de secreções cutâneas que poderiam provocar erupções na pele. Tais instruções deveriam ser seguidas principalmente nos orfanatos.

Quanto à forma de se vestir das mulheres, uma preocupação registrada nos discursos dos médicos higienistas desse período enreda-se em críticas aos imperativos da moda. Para o Dr. Coutinho, por exemplo, a moda não deveria entrar nas casas de educação, e os vestidos das mulheres deveriam garantir que as funções do organismo fossem respeitadas. Nesse sentido, o uso do espartilho era condenado por ser considerado prejudicial à saúde; tal acessório poderia desfigurar o corpo e dificultar seu completo desenvolvimento, pois comprimia o tórax e o 
fígado, bem como comprometia a respiração e a circulação adequadas. A crítica estendia-se, ainda, aos decotes dos vestidos, por não cobrirem apropriadamente o corpo e por não o protegerem da umidade e do frio, o que ocasionava várias doenças, tais como bronquite, afecções dos órgãos e "phithysica", além de "sacrificar" o pudor, "forte baluarte da virtude que separa a mulher honesta do mundo de lascívias" (GONDRA, 2004, p. 186).

Articulada aos ditames sociais, a forma de se vestir dos alunos deveria basear-se nos fundamentos da medicina e da higiene, que tinham "a função de vestir e proteger o corpo de modo adequado" (p.187). As escolas, por sua vez, deveriam proibir um vestuário baseado na moda, principalmente para as meninas, visto que estas estavam mais sujeitas às tentações. Assim, além da "forte presença de um argumento que prevê o respeito à natureza biológica e ao ambiente local como modo de atender às funções do organismo" (p. 185), o posicionamento médico apresentava-se bem alinhado no combate aos imperativos da moda e continha um forte apelo moral.

Tal discurso médico foi sendo incorporado pela escola e pelos educadores, a exemplo das críticas elaboradas por Pablo Pizzurno, educador com grande experiência no sistema educativo argentino, considerado um dos inventores do guardapó e do uniforme naquele país, no início do século XX. Segundo Pizzurno, o luxo e a ostentação das mulheres estavam centrados na frivolidade, de modo que $o$ amor às vestimentas caras podia levar a ofícios não santos. Ele afırma que a moda não era importante se as roupas fossem limpas e cômodas, e se, acima de tudo, as meninas que as usassem fossem bem comportadas, pois

La gente sensata, educada e com gusto se vieste simplesmente, tratando de no llamar la atención, y tomando em cuenta, sobre todo, las regras higiências a las que debe someterse la ropa. (PIZZURNO apud DUSSEL, 2005, p. 72)
Em relação às terras catarinenses, apresentamos alguns dados sobre um dos intelectuais mais destacados no cenário educacional da primeira metade do século XX: Oswaldo Rodrigues Cabral ${ }^{1}$ (nascido em 1903). Aluno do curso de medicina da Faculdade de Medicina do Rio de Janeiro e ex-professor primário em Santa Catarina, ele defendia a tese de que se fazia necessário educar a população, substituindo hábitos considerados condenáveis por outros sãos e recomendáveis. Em seu trabalho de conclusão do curso de medicina, intitulado Problemas educacionaes de hygiene, defendido em $1929^{2}$ e aprovado com distinção, ele afırma a necessária educação sanitária do povo como meio de regeneração social. Ideias alinhadas a essa tese foram apresentadas na $1^{a}$ Conferência Estadual de Ensino Primário, realizada em Florianópolis em 1927, por meio do trabalho intitulado $O$ ensino de noções de hygiene nas escolas públicas do Estado de Santa Catarina.

Para Cabral (1929), era preciso educar o povo, incutindo-lhe noções elementares de higiene e de medicina preventiva em prol do saneamento e da saúde de todos, para se ter, "no futuro, mais bellos, mais perfeitos exemplares de uma raça nova" (p. 11). Seu trabalho ganha especial relevância devido aos lugares por onde passou e aos poderes que acumulou. Cabral começou sua carreira como professor primário em 1919, na cidade de São Francisco do Sul, em Santa Catarina, após ter concluído o curso de habilitação no magistério primário da Escola Normal Catharinense. Formado em medicina em 1929, ele atuou posteriormente como historiador, professor universitário e político. Depois de graduado, atuou como livre-docente de medicina legal, na Faculdade de Direito, e mais tarde lecionou em várias áreas de humanidades. $\mathrm{Na}$

1 - Oswaldo Rodrigues Cabral foi autor de vários livros sobre Santa Catarina, nas mais diversas áreas, desde temas ligados à medicina, até folclore e ficção. Foi idealizador, fundador e primeiro diretor do Museu Universitário de Santa Catarina, denominado, a partir de 1993, Museu Oswaldo Rodrigues Cabral.

2 - Segundo o próprio Oswaldo Rodrigues Cabral, a tese de uma intensa campanha de educação sanitária a ser aplicada nas escolas era por ele defendida há alguns anos e suas propostas vinham sendo publicadas na imprensa catarinense. 
cena política, ocupou a legislatura de Deputado Estadual no período entre 1947 e 1951, além de ter ocupado o cargo de diretor da Assistência Municipal de Florianópolis durante o Estado Novo. Faleceu em 1978, aos 74 anos de idade, deixando um legado de escritos e adeptos.

Num discurso direto, ao referir-se aos cuidados com o vestuário, Osvaldo Rodrigues Cabral (1929) indicava que, desde o primeiro dia de aula, o professor deveria exigir de seus alunos que se apresentassem com suas roupinhas perfeitamente limpas e que tivessem cuidado com suas próprias roupas e com as de seus colegas. Ele asseverava, ainda, que a adoção de aventais brancos por alguns Estados brasileiros era a medida mais adequada, pois evitava que, por qualquer acidente, a criança viesse a sujar suas roupas, considerando-o assim um meio econômico e higiênico. No entanto, declarava que, tanto com as roupas quanto com os aventais, dever-se-ia ter os mesmos cuidados. No caso de, por algum motivo, a roupa ficar molhada, Cabral indicava que ela fosse imediatamente substituída. Seria ainda bastante desejável que se pudesse exigir das crianças que utilizassem as roupas conforme as estações do ano (lã para o inverno e algodão para o verão) e que as cores fossem de acordo com a condutibidade e a irradiação do calor. Acrescentava, ainda, a necessidade do uso de calçados. ${ }^{3}$

De acordo com ele, desde o primeiro dia na escola, o professor deveria ir corrigindo e imprimindo novos costumes nos discentes, procurando aproveitar os bons e substituir por novos aqueles "imprestáveis", habituando os alunos a uma prática correta de "boas ações higiênicas" até que eles as pratiquem automaticamente e que "estejam estes hábitos adquiridos de tal forma, que sigam os indivíduos além da escola, para toda a vida" (CABRAL, 1929, p. 37). A prática de tais atos saudáveis deveria ser exigida e corrigida cotidiana e minuciosamente por meio de vigilância constante, tomando-

3 - Apesar de considerar tais medidas de extrema importância, Cabral reconhecia que a falta de recursos entre a população pobre inviabilizaria sua adoção. -se cuidado com os detalhes. Conforme aponta Gondra (2004), "na perspectiva higienista, era a partir do ordenamento dos detalhes que o ordenamento mais geral estaria garantido" (p. 191).

Amparada em preceitos higienistas, ao situar a roupa como preservação da saúde e do pudor e como critério para adoção de uma estética, a escola construiu estratégias de intervenção sobre os corpos dos alunos, disciplinando-os de modo a torná-los adequados para circular na emergente e idealizada sociedade: limpa, ordenada, sã e, enfım, civilizada, já que a roupa/uniforme esculpe uma conduta e reflete uma dada organização social.

0 aparato moral presente nesses discursos irá ter grandes reflexos na indicação dos modelos dos uniformes escolares, principalmente para as alunas e para as professoras, irradiadoras da forma adequada, austera e bem-comportada de vestir-se ${ }^{4}$. A exigência expressa nos regulamentos das escolas sobre a obrigatoriedade de usar uniformes bem-comportados será uma constante no meio escolar e perdurará por décadas, tanto nas escolas públicas quanto nas particulares. Para as alunas e professoras, a regra é blusas sem decotes e saias com comprimento abaixo dos joelhos.

\section{Uniformizando os corpos dos escolares}

Se durante o século XIX não havia ainda uma prescrição mais agressiva acerca do uso de uniformes padronizados para os alunos das escolas públicas brasileiras, com o advento da República e a expansão do ensino, tal prescrição ganha força. Um dos argumentos fortes para a adoção do uniforme, conforme aponta Inês Dussel (2005), foi a ideia de que, por meio dele, seria possível evitar o contraste entre ricos e pobres, tão caro à concepção de democratização do ensino ${ }^{5}$. Ao

4 - Ver, a esse respeito, o capítulo intitulado Do corpo exigido, na tese de doutorado de Vera Lúcia Gaspar da Silva (2004).

5- É importante registrar que a autora mencionada toma por referência 0 contexto argentino; contudo, consideramos oportuno agregar aqui essa reflexão. 
se constituírem como símbolos de padronização, os uniformes foram considerados um elemento fundamental para a construção de um sistema educacional que postulava uma educação igual para todos. No caso brasileiro, sabemos que a igualdade pretendida escondia diferenças significativas.

Em nome da democratização do ensino foram criadas, no Brasil, várias estratégias e políticas públicas com o objetivo de fazer com que os alunos permanecessem na escola, a exemplo das Caixas Escolares, das Fundações Educacionais, da Seção de Orientação e Assistência Escolar. Essas instituições caracterizavam-se como auxiliares, destinadas, entre outros benefícios, à compra de vestuário e calçados para os alunos que não tivessem condições de adquiri-los. Vemos aqui uma engenhosa forma de responsabilizar a comunidade por assegurar o cumprimento de desejos, desafios e normas imputadas pelo Estado.

0 Relatório da Conferência Interestadual de Ensino Primário, de 1922, indicado no trabalho de Solange Aparecida de Oliveira Holler (2009), ao referir-se à obrigatoriedade de ensino como essencial, afırmava que

a obrigatoriedade da frequência exige um serviço de assistência aos alumnos indigentes, aos quais teem de ser fornecidos livros e material escolar como em muitos casos até vestidos e alimentação. (p. 56)

Em 1960, essa preocupação ainda estava presente. As emendas à $1^{\text {a }}$ convenção em defesa da escola pública ao projeto de diretrizes e bases, publicadas na Revista Brasileira de Estudos Pedagógicos daquele ano, irão indicar que o direito à educação deverá ser assegurado, entre outros benefícios, pela gratuidade escolar e

pela assistência aos alunos que dela necessitarem, sob forma de fornecimento gratuito, ou a preço reduzido, de material escolar, vestuário, alimentação e serviços médicos e dentários. (p. 88)
A partir desses indicativos, podemos perceber que o auxílio para a permanência dos alunos na escola respondia por várias estratégias; durante grande parte do século XX, garantir o vestuário figurava como um dos itens importantes.

Em Santa Catarina, a preocupação com a vestimenta dos alunos já aparecia expressa no Regulamento Geral da Instrução Pública de 1908 (Decreto $\mathrm{n}^{\circ}$ 348), o qual previa auxílio para aquisição de "vestuário e calçados simples, adequados ao sexo e ao clima", aos menores que, por carência absoluta de meios, não pudessem adquiri-los. Nas fontes pesquisadas, identificamos que, em 19386, o governo catarinense tornou obrigatório o uso de uniformes por meio do Decreto-Lei ${ }^{\circ}$ 88, mas sem determinar o modelo, indicando apenas que sua aprovação ficaria a cargo do Departamento de Educação. Somente em 1946 o governo apresentou um plano detalhado de uniformes tanto para os professores quanto para os alunos, a partir dos regulamentos para os estabelecimentos de ensino primário (Decreto $n^{\circ}$ 3.735) e ensino normal (Decreto $n^{\circ}$ 3.674) do Estado de Santa Catarina.

Para os alunos do ensino primário, o Decreto determinava que fosse adotado um modelo de uniforme conforme a figura 1 . Para os meninos: blusa branca tipo esporte, manga comprida com punho virado, bolsinho no lado esquerdo com as iniciais do educandário; calça azul marinho; cinto da mesma fazenda, na cor branca, com fivela de metal; e boné branco tipo bibi. Para as meninas, o uniforme deveria ser constituído por: blusa branca tipo esporte; manga curta com punho virado; bolsinho no lado esquerdo com as iniciais do educandário; saia azul marinho pregueada; cinto da mesma fazenda na cor branca, com fivela de metal.

6 - Estamos no período marcado na história como Estado Novo e, em Santa Catarina, houve forte intervenção do Estado visando nacionalizar a população, composta, em algumas regiões, basicamente por estrangeiros. 
Figura 1 - Modelo de uniforme de uso diário para os sexos masculino e feminino
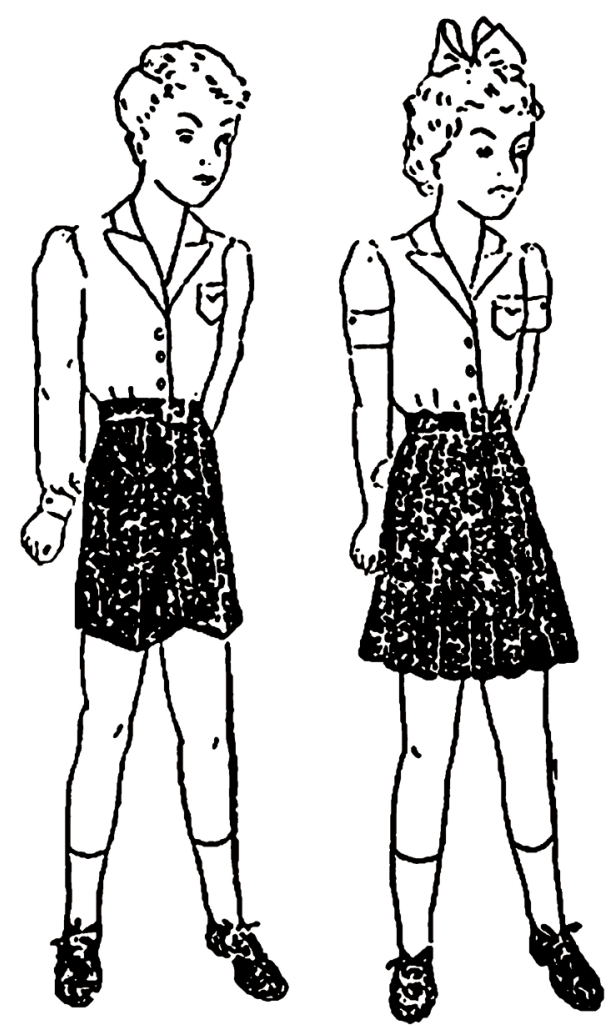

Fonte: Regulamento para os Estabelecimentos de Ensino Primário no Estado de Santa Catarina (Decreto n ${ }^{0} 3.735$, de 17 de dezembro de 1946).

Para as aulas de educação física, o uniforme deveria seguir as especificações apresentadas na figura 2. Para os meninos: camisa de meia sem manga, na cor branca; calção azul marinho com elástico na cintura e sapatos de tênis brancos. Para as meninas: blusa branca tipo esporte, com manga curta, punho virado e bolsinho no lado esquerdo; bombacha preta com elástico na cintura e sapatos de tênis brancos, conforme os modelos a seguir. Permitia-se, ainda, que fossem aproveitadas algumas peças do uniforme diário para as atividades de educação física: a calça azul marinho para os meninos e a blusa branca para as meninas. E, para os dias frios, além da camisa de meia, os alunos poderiam usar a blusa do uniforme diário.
Figura 2 - Modelo de uniforme de educação física para os sexos masculino e feminino
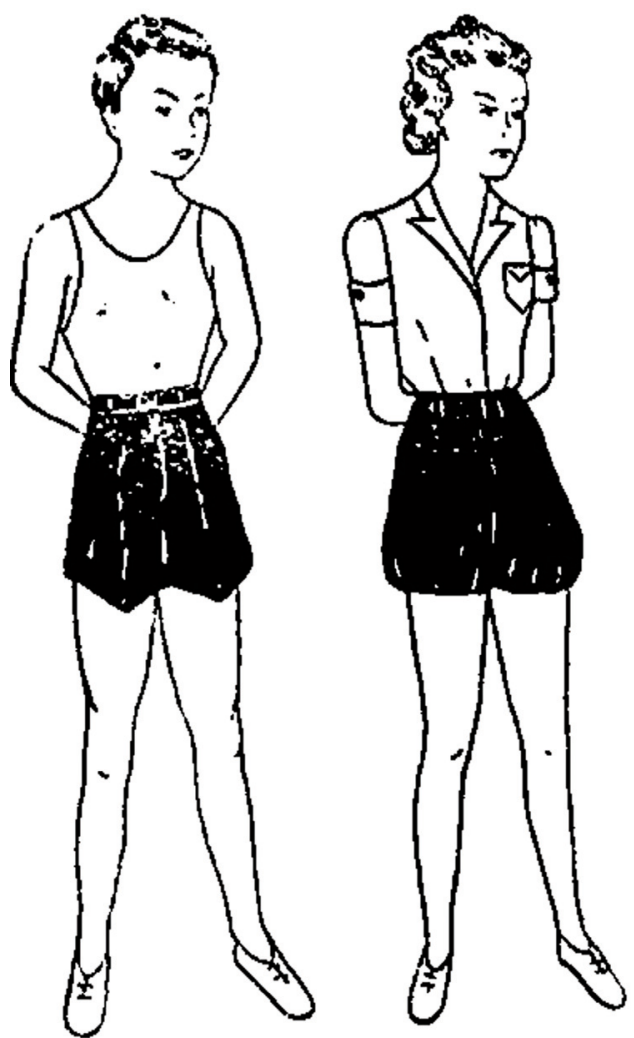

Fonte: Regulamento para os Estabelecimentos de Ensino Primário no Estado de Santa Catarina (Decreto n 3.735 , de 17 de dezembro de 1946).

Tais modelos deveriam ser adotados pelas escolas estaduais e municipais. Quanto aos estabelecimentos de ensino particulares, estes poderiam seguir o mesmo modelo, desde que fossem observadas disposições indicadas no Decreto-Lei ${ }^{\circ} 88$, de 31 de março de $1938^{7}$.

Apesar de essa prescrição detalhada dos modelos ser identificada na legislação estadual somente em 1946, os alunos das escolas públicas de Santa Catarina já utilizavam, na década de 1920, um modelo de uniforme muito próximo ao prescrito quase trinta anos depois, conforme observado na pesquisa de mestrado de Solange Aparecida de Oliveira Hoeller (2009)

7- 0 referido decreto determinava que os estabelecimentos particulares de ensino deveriam adotar uniformes escolares desde que fosse mantido mais de um curso, submetendo-os previamente à aprovação do Departamento de Educação, que poderia determinar as modificações que julgasse necessárias. 
sobre a escolarização da infância catarinense no período de 1910 a 1935. No entanto, uma questão importante pode ser observada entre as vestimentas utilizadas pelos alunos que frequentavam os grupos escolares e as das escolas isoladas. As fotografias apresentadas na referida pesquisa demonstram que, enquanto as crianças dos grupos escolares, em sua maioria, faziam uso de uniforme, as frequentadoras das escolas isoladas utilizavam roupas de diferentes modelos e cores, sendo que a maioria dos alunos não fazia uso de calçados. Tal circunstância está retratada nas figuras 3 e 4.

Figura 3 - Alunos de uma escola isolada catarinense da década de 1920

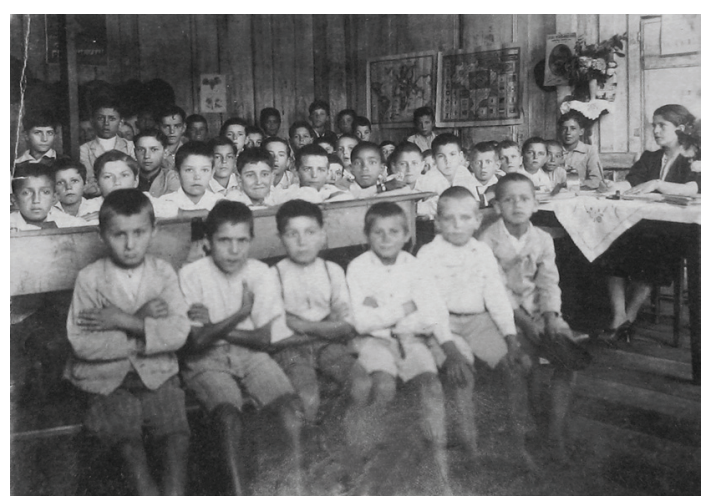

Fonte: HOELLER, 2009.

Figura 4 - Alunos de um grupo escolar catarinense da década de 1920

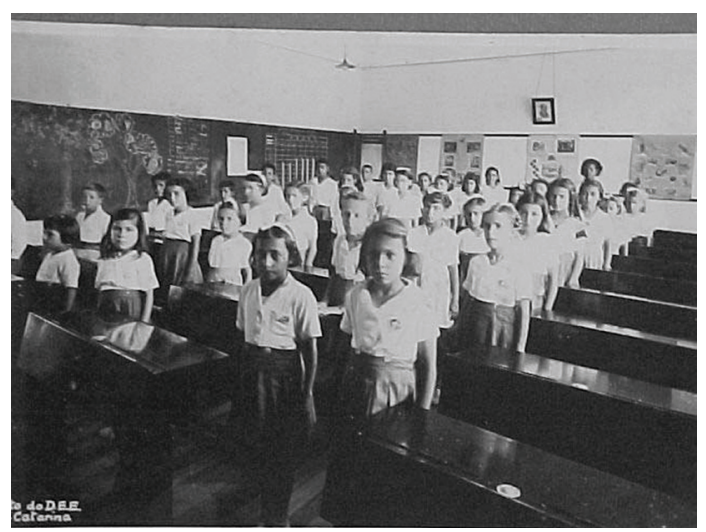

Fonte: HOELLER, 2009.
Tais características denunciam as enormes diferenças existentes entre as duas modalidades de ensino. Enquanto os grupos escolares agregavam "o que, em termos de ensino, havia de melhor à época” (GASPAR DA SILVA, 2006, p. 181) - edifícios construídos especialmente para esse fim, em locais de grande visibilidade, com mobiliário adequado aos preceitos higiênicos e com os melhores recursos didático-pedagógicos, além de disporem de professores considerados os mais eficientes -, as escolas isoladas apresentavam uma realidade não raramente oposta - casas de madeira com bancos pouco ou nada adaptados, um só professor lecionando a um grupo de alunos com níveis de ensino diferenciados, além de conteúdos distintos dos adotados pelos grupos escolares.

Importa lembrar aqui que os grupos escolares fizeram parte do projeto republicano de reinvenção das cidades, que procurava adequar a população aos padrões de urbanidade e modernidade. Nesse projeto, os uniformes escolares constituíram-se como um elemento importante, pois a visibilidade pretendida por essas instituições modelares também perpassava as vestimentas utilizadas pelos alunos; nesse caso, a adoção de um modelo único representaria, além de um aspecto de ordenamento e disciplina, o pressuposto aparente de igualdade de condições. Os uniformes prestavam-se, assim, a padronizar os alunos, mascarando as condições sociais por meio de um modelo único de roupa.

No entanto, essa visibilidade pretendida pela República por intermédio dos grupos escolares não implicou a democratização efetiva de acesso à escola, visto que "amplos setores da população brasileira continuavam excluídos do processo educacional" (VEIGA, 2007, p. 247). 0 projeto republicano de modernização e progresso a ser atingido pela educação pública via grupos escolares não atingiu a todos, e as especificidades expressas no vestuário utilizado pelos alunos dos centros urbanos e do meio rural denunciam tal exclusão.

Mas se as diferenças eram mais marcantes entre os grupos escolares e as escolas 
isoladas, no meio urbano, muitas crianças ficaram excluídas do processo de escolarização, e mesmo as que conseguiam frequentar os grupos escolares sofriam processos de exclusão. É o que um olhar mais atento sobre as imagens apresentadas no trabalho de Solange Aparecida de Oliveira Hoeller (2009) apontam. Na figura 5, percebe-se que nem todas as crianças utilizam uniformes e que aquelas que estão uniformizadas recebem destaque no cerimonial. Quanto à figura 6, um olhar desatento nos levará a pensar que todas as alunas estão uniformizadas, mas, se atentarmos para os detalhes dos calçados, veremos que algumas fazem uso dele, enquanto outras não.

Figura 5 - Encerramento do ano letivo do Grupo Escolar Paulo Zimmermann de Rio do Sul, em 1937

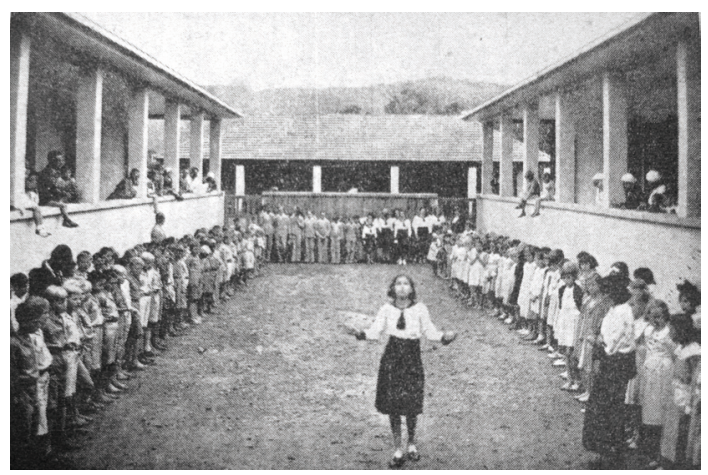

Fonte: HOELLER, 2009.

Figura 6 - Turma feminina de um grupo escolar catarinense da década de 1920

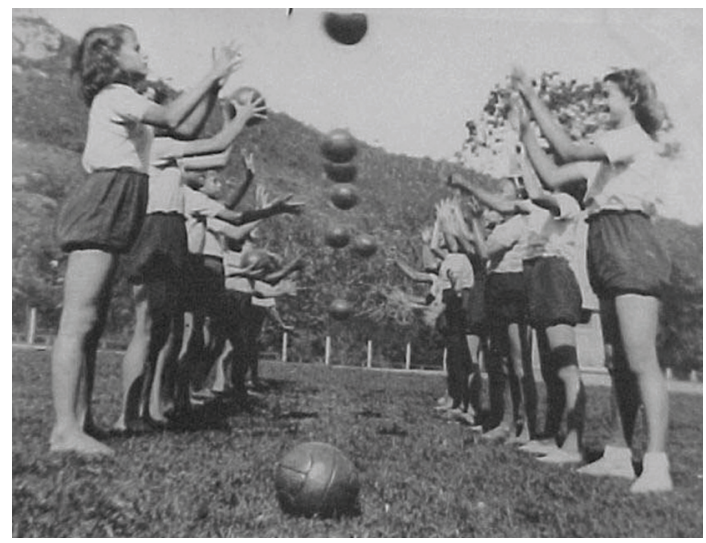

Fonte: HOELLER, 2009.
Tais diferenças expressas nos uniformes dos(as) alunos(as) indiciam condições materiais desiguais entre as crianças que frequentavam os grupos escolares, as escolas isoladas ou as demais instituições educativas existentes no Estado, tais como a Escola de Aprendizes Artífices e o Abrigo de Menores. Elas assinalam, ainda, que a igualdade proposta pelo uniforme é apenas aparente, pois os marcadores sociais não desaparecem com seu uso, visto que as diferenças permanecem presentes nos detalhes: na linguagem, no consumo, nas disposições culturais e estéticas. Por isso, segundo Inês Dussel (2005), os uniformes escolares, mesmo sendo uma medida com proposta pautada nos princípios de igualdade, também provocam exclusões e impõem hierarquias e desigualdades: de gênero, sociais, raciais e culturais.

A pesquisa de Katiene Nogueira da Silva (2006), que se refere ao período de expansão da escola pública paulista (1950-1970), identifica ter havido, também naquele período, no Estado de São Paulo, uma tentativa de padronizar os alunos que adentravam a escola por meio da adoção de uniformes, de modo a impedir que a miséria se tornasse evidente. No entanto, conforme afirma a autora, a escola pública paulista não atingiu seu intento. Ao contrário, acabou excluindo muitos alunos, pois só poderiam permanecer na escola aqueles que atendessem às exigências materiais que lhes eram impostas, tanto em relação aos uniformes, quanto aos materiais escolares e ao transporte. Estamos aqui diante de um paradoxo: ao mesmo tempo em que se pretendia alcançar uma expansão da escola pública, exigia-se que os alunos tivessem determinada condição financeira para frequentá-la. Além disso, "vestir os uniformes escolares constituía uma regra imposta por normas regimentais e fazia parte da disciplina escolar, não vesti-los caracterizava uma transgressão passível de punição" (SILVA, 2006, p. 191). Há evidências, apontadas em diferentes trabalhos de que muitos foram punidos e excluídos do processo de escolarização por falta do uniforme. 
Os dados e as reflexões apresentadas indiciam dois movimentos (ou tensões) nada desprezíveis. Por um lado, são evidentes as dificuldades encontradas para adoção dos uniformes escolares para todos os alunos, tanto por parte do Estado quanto por parte das famílias, devido ao fato de representarem um custo elevado, principalmente os calçados, artigos pouco utilizados pela maioria da população no início do século XX. Por outro lado, há indícios de que esse traje desempenhava uma função niveladora importante. Por meio dele, criava-se uma ideia de padronização e democratização do ensino, mesmo que em aparência, além de se conceder visi- bilidade pública a uma instituição social cada vez mais importante: a escola. É possível que o desejo de dar visibilidade a uma ação governamental ou a um empreendimento privado se sobreponha, em muitos momentos, à intenção de oferecer oportunidades iguais e minimizar diferenças que estariam mais expostas sem o uso de tal fardamento. Porém, se entendemos que a materialidade não é desinteressada, mas que ela também educa, devemos manter atenção e agregar outros elementos à reflexão a fim de favorecer a construção de uma compreensão mais acurada da presença desses artefatos, sejam eles vestimentas ou acessórios que compõem uma estética escolar.

\section{Referências}

BOUDRILLARD, Jean. 0 sistema dos objetos. São Paulo: Perspectiva, 1968.

BUCAILLLE, Richard; PESEZ, Jean-Marie. Cultura material. In: Enciclopédia Einaudi. v. 16. Portugal: Imprensa Nacional; Casa da Moeda, 1989. p. 11-47.

CABRAL, Oswaldo Rodrigues. Problemas educacionaes de hygiene. Trabalho apresentado como fim de obter Grau de Doutor em Medicina, 1929.

DUSSEL, Inês. Cuando las aparecias no engañan: uma historia comparada de los uniformes escolares em Argentina y Estados Unidos (siglos XIX-XX). Pro-Posições, Campinas, v. 16, n. I (46), p. 65-86, jan./abr. 2005.

. Los uniformes como políticas del cuerpo: um acercamiento foucaultiano a la historia y el presente de los cógidos de vestimenta en la escuela. In: GÓMEZ, Zandra Pedraza. Políticas y estéticas de cuerpo em América Latina. Bogotá: Universidad de los Andes, Faculdad de Ciencias Sociales, Departamento de Antropología, CESO, Ediciones Uniandes, 2007.

ECO, Umberto. Psicologia do vestir. Lisboa: Assírio e Alvim. 1989.

Emendas a $1^{\text {a }}$ Convenção em defesa da escola pública ao projeto de Diretrizes e Bases. Revista Brasileira de Estudos Pedagógicos, n. 79, pp. 87-100, jul./set., 1960.

ESCOLANO BENITO, Agustín. Patrimonio material de la escuela e historia cultural. Revista Linhas, Florianópolis, v. 11, n. 2, p.1328, jul./dez. 2010.

GASPAR DA SILVA, Vera Lúcia. Do corpo exigido. In: Sentidos da profissão docente. Tese (Doutorado em Educação) Faculdade de Educação, Universidade de São Paulo, São Paulo, 2004. p. 129-167.

Vitrines da República: os grupos escolares em Santa Catarina (1889-1930). In: VIDAL, Diana Gonçalves (Org.). Grupos escolares: cultura escolar primária e escolarização da infância no Brasil (1893-1971). São Paulo: Companhia das Letras, 2006. p. 341-376. 
GONDRA, José. Artes de civilizar: medicina, higiene e educação escolar na corte imperial. Rio de Janeiro: UERJ, 2004.

GVIRTZ, Silvina (Compiladora). Textos para repensar el día a dia escolar: sobre cuerpos, vestuários, espacios, lenguajes, ritos y modos de convivência em nuestra escuela. Buenos Aires: Santillana, 2005.

HOELLER, Solange Aparecida de Oliveira. Escolarização da infância catarinense: a normatização do ensino público primário (1910-1935). Dissertação (Mestrado) - Universidade Federal do Paraná, Curitiba, 2009.

MENESES, Ulpiano B. A exposição museológica e o conhecimento histórico. In: FIGUEIREDO, Betânia Gonçalves; VIDAL, Diana Gonçalves. Museus: dos gabinetes de curiosidades à museologia moderna. Belo Horizonte: Argvmentvm, 2005. p. 18-84.

NÓVOA, António; SCHRIEWER, Jürgen (Eds.). A difusão mundial da escola. Lisboa: Educa, 2000.

ROCHE, Daniel. História das coisas banais: nascimento do consumo séc. XVII-XIX. Rio de Janeiro: Rocco, 2000.

SANTA CATARINA. Decreto n. 348, de 07 de Dezembro de 1907. Regulamento Geral da Instrução Pública do Estado de Santa Catarina em execução da Lei n. 846 de 11 de outubro de 1910.

Decreto n. 3.674, de 23 de novembro de 1946. Regulamento para os estabelecimentos de ensino normal no Estado de Santa Catarina.

Decreto n. 3.735, de 17 de dezembro de 1946. Regulamento para os estabelecimentos de ensino primário no Estado de Santa Catarina.

Decreto-Lei n. 88, de 31 de março de 1938. Normas relativas ao ensino primário, em escolas particulares do Estado.

SILVA, Katiene Nogueira da. Criança calçada, criança sadia: sobre os uniformes escolares na escola pública paulista entre os anos de 1950 a 1970. Dissertação (Mestrado) - Universidade de São Paulo, São Paulo, 2006.

SOUZA, Rosa Fátima de Souza. Alicerces da pátria: história da escola primária no estado de São Paulo (1890-1976). Campinas: Mercado das Letras, 2009.

VEIGA, Cynthia Greive. História da educação. São Paulo: Ática, 2007.

Recebido em: 17.04.2012

Aprovado em: 28.05.2012

Ivanir Ribeiro é psicóloga educacional do Instituto Federal de Educação de Santa Catarina (IFSC) e mestre em Educação pelo Programa de Pós Graduação em Educação da Universidade do Estado de Santa Catarina (UDESC). E-mail: ivanir@ifsc.edu.br.

Vera Lucia Gaspar da Silva é professora associada da Universidade do Estado de Santa Catarina (FAED/UDESC), doutora em História e Historiografia da Educação e sócio-fundadora da Sociedade Brasileira de História da Educação. E-mail: vera.gaspar@floripa.com.br. 